\title{
Transnational Actors and Local Development in Ethiopia: The Experience of World Vision in Lalo Assabi and Nadjo Districts
}

\author{
Ebssa Wakwaya Gonfa \\ Wollega University, Department of Political Science and International Relations
}

\begin{abstract}
Transnational actors' are increasingly becoming important development partners almost everywhere in the contemporary world. Yet, due attention is not given to what this development means in general and how these actors function at grass root level; especially in developing countries like Ethiopia. This study explores the role of INGOs in local development processes in Ethiopia focusing on the experience of World Vision in Lalo Assabi and Nejo Woredas of Oromia regional state. In doing so, the study follows qualitative research approach and is based on both primary and secondary data. The overall finding of the work is that World Vision's conception of development is based on both altruism and strategic considerations including its recent 'integrated development approach'. In practice, the organization is working with already established institutions to support development based on the set priority areas. However, while it is possible to expect significant contribution merely by looking at the allocated budget, lack of transparency on the details hinders the study to substantiate the supposed contributions. Rather, the organization's effort to adopt some innovative approaches in the areas of education and food security can be considered as more meaningful. As expected in Campbell's frame work, the organizations focus on 'development' and its approach of 'partnership' seems to explain the existing positive relationship with local government bodies as well. Finally, the organization's identity as a transnational actor has also significant bearings on its image and autonomy. Accordingly, one may recommend that along with being alert to national and global realities, it is also required to consider the development expectations and demands of local community correspondingly.
\end{abstract}

Key words-Transnational actors, Local development, Partnership

\section{I.INTRODUCTION}

This is the age when powerful trans-national actors like NGOs increasingly share the stage with governments in diverse ways (Keohane and Nye :1971). More recently, as Nye precisely indicates, "even large countries with hard power, such as the United States, find themselves sharing the stage with new actors and having more trouble controlling their borders." (2007:247). Moreover, others argue that the world we are living in now is qualitatively different and post- Westphalian state is expected to play qualitatively different role to remain relevant. According to this view, "governments are choosing, or being forced, to share power in many ways" and generally we are in the age of 'civicus' when different forms of civil society is coming to world stage vigorously with different approaches to development and governance at global scale (Clark, 2006:91). On balance, now it is increasingly becoming difficult to ignore the role of transnational actors whether we are dealing with domestic or international issues.

In our context, the proliferation of NGOs in Ethiopia is related to the two great famines and the subsequent response by northern NGOs in emergency lifesaving operations. Then after, they begun to expand their operation by supporting many rural development schemes (Kassahun, 2002). According to the registry of Ministry of Justice (2007) a total of 2,305 organizations have acquired legal registration at federal level; of which international NGOs constituted 234. The bulk of NGO resources in Ethiopia also invested on human development (health, education, child welfare) agriculture and food security. Indeed, according to some authors, NGOs generally operate "inside the framework of the country's development and poverty reduction plans and strategies." (Dessalegn et al, 2008: 7)

However, beyond such discussions about their relevance at international and national levels, less effort is exerted to explore the experience at grass root level in the context of most developing countries. To get the full picture, we have to also explore the unique experiences at grass root level and connect it to the macro level discussions. As such this study aims to focus only on development NGOs in Lalo Assabi and Najo Woredas in West Wollega administrative Zone of Oromia regional State. Even within this limited scope, it deals with the experience of WVE as it is the only established international NGO which is currently active in the area. 
In this context, this study deals with WV's conception of and role in development, the implications of its transnational identity and perceptions about it on its relations with other stake holders as a case study based on the following research questions:

1. How WV conceives local development and what makes its approach different in these areas?

2. What are the major contributions of WV in these areas regarding local development and how it can be related to government's approach?

3. How its transnational nature is affecting its image, autonomy and relations with local government bodies and the community?

\section{II.MATERIALS AND METHODS}

The research is basically exploratory and relays on the paradigm of Transnationalism that attempts to explain complex interactions at global scale by complementing the conventional 'state centered' approaches in IR. As such, while being sensitive to the significant power States may retain to this date, it employs deductive approach to explore the experience of WV in the study area as a case study. However, ultimately the purpose is to explain the diverse outcomes of transactions that transcend the conventional borders as we knew them. As a data source, it is based on both primary and secondary data. More specifically, while it is primarily based on secondary data sources, complimenting it with primary data is considered as a necessity especially when we have to deal with the experiences at grass root level. As such, to collect secondary data it relays on both published and un published materials like books, journals, reports and other on line resources. In addition, relevant primary data is also collected by using semi-structured interview with key informants and personal observation.

Finally, the analysis of the collected data is made qualitatively based on the forwarded research design by using the selected concepts as a guide to explore and explain the identified research questions. In addition, this is also complimented by discourse analyses that may help us to reflect on less tangible and subjective understandings about each other by relevant actors. Ultimately, it attempts to see the connection between local experiences and the assumptions at national and global level about the role of such organizations in local development through meticulous qualitative analysis.

\section{III.THEORETICAL AND CONTEXTUAL DISCUSSION}

Transnationalism is often considered as an alternative to nationalism in the contemporary world. According to Rourke (2005) this 'new' development is based on two inter related changes- globalization and human thought. First, the increasing interconnectedness worldwide as a result of globalization makes people to interact often transitionally; and become aware about their interdependence in many ways. Then, the second source- human thought is too abstract and related to imagination about how people see themselves beyond what they have experienced life traditionally. Thus, it may base on ideologies, religion, ethnicity, gender or any other terms of self-understanding which is not bounded to national boundaries. From this perspective, we may consider diverse actions as transnational actions if their activities cross national boundaries whether they are individuals, groups, states and other organizations.

In this context, transnational actors include states, international organizations, NGOs, MNCs, and even indigenous nationalists and terrorist networks. (Kegley and Banton, 2011). Consequently, such evolution in international relations as a practice paves the way for the emergence of new approaches to deal with the new dynamics which are largely ignored by conventional approaches in IR. These emerging paradigms include transnationalism, pluralism, international regimes and global governance. However, while these paradigms have much in common, this study relays only on the former- transnationalism.

However, this focus on non-state actors is not at the cost of ignoring state by considering it as obsolete. Rather it is to supplement the convectional approaches which are state centric by incorporating the emerging actors like NGOs as they do have significance impact on the making of the contemporary world. In another words, the study of transnational relations focusses not only on interactions among non-governmental entities, but also the relations among states and between state and non-governmental entities (Rosenal,1980). In the context of such emerging transnational network, the study adopts a framework developed by Campbell to explain the nature of NGO-State relations in the context of the study area. 


\begin{tabular}{|l|ccc|}
\hline \multirow{2}{*}{ NGO functions } & \multicolumn{3}{|c|}{ Regime Types } \\
\hline $\begin{array}{l}\text { Welfare } \\
\text { provision }\end{array}$ & ++ & + & Military dictatorship \\
\cline { 2 - 4 } $\begin{array}{l}\text { Grass-roots } \\
\text { development }\end{array}$ & + & 0 & - \\
$\begin{array}{l}\text { Advocacy/Human } \\
\text { Rights }\end{array}$ & & & -- \\
\end{tabular}

Figure 1- Ideal Types of State- NGO relations. Adopted from Campbell (1996:5)

In a net shell, this frame work is developed by Campbell based on two characteristics- regime types and NGOs functions. According to him, the first is based on the suggestion by John Clark regarding what is expected from three categories of regimes. The idea is that in liberal democracy NGOs are generally welcomed and considered as integral part of civil society while in the single party states they can be tolerated only if their projects complement the government development policy. However, in military dictatorship NGOs in general face the most difficult challenge even to survive. The second one is based on NGOs function and purpose. While NGOs engaging in welfare provision are less likely to experience conflict with states, those engaging in advocacy and human right work are more likely to have hostile relations with governments even when tolerated. In sum, the above figure illustrates the potential/ expected outcomes based on the conjunction of these two factors.

\section{IV.TRANSNATIONAL NGOs' ROLE IN LOCAL DEVELOPMENT}

According to David Korten (1987), most NGOs pass through three generation of program strategy. For him they often begun with doing relief and welfare work, then move on to small scale self-reliant development works, and finally involve themselves in sustainable system development. In line with this, he distinguishes between NGOs that focus on humanitarian assistance and those focusing on development assistance. This is also similar to what Clark calls a 'curative' rather than 'preventive' approach to development programs (cited in Edwards and Hulme, 1992). On the other hand, others tend to focus on the basic roles NGOs play in the contemporary development practice. These include service delivery, catalysis and partnership while these activities can be also combined within a particular NGOs functions (Lewis and Kanji, 2009).

Whatever the case, since the turn of the $21^{\text {st }} \mathrm{c}$ NGOs seem to get first hand in providing development assistance. Reasons for this development include: a general shift of thinking about development and the importance of human capital, and a shift to a more humanistic conception of development (World Bank, 2002). On the other hand, some also point to the ascendance of free market and the related view on the limitations of government agencies in providing services as a result of SAP that requires them to cut public expenditure.

In this context, this study focuses on Lewis and Kanji's characterization of three main roles of NGOs in the contemporary development practice- service delivery, catalysis and partnership. Briefly, while these three basic roles can be seen as organizational specializations, NGOs are increasingly engaging in combining these roles. In doing this they also need to develop the qualities of a learning organizations like openness, self-criticism, and cooperative spirit to build credible alternatives and improve their impact. (Edwards and Hulme, 1992).

\section{V.OVERVIEW OF NGOS EXPERIENCE IN ETHIOPIA}

The emergence of NGOs in general and INGOs in particular is recent phenomena in Ethiopia, even when compared to other African states. Generally, one can point only to a few NGOs until 1970s which by themselves were "ecumenical in orientation, foreign based, and mainly engaged in social welfare and community development programs of limited scope" (Kassahun, 2002:121). Beyond their limited scope, these "first generation' NGOs in Ethiopia were also largely limited geographically to Addis Ababa and they were functioning only when conforming with the will of government officials (ibid).

Whatever the case, the massive influx of NGOs in Ethiopia was intimately linked to two great famines in the recent history of the country. First, the tragic famine in the early 1970 s become beyond the ability of state to 
manage and the imperial government was forced to open its door to NGOs. Then, similar famine in the mid1980s compelledthe Derg Regime to respond in a similar way and allow further expansion in the number of NGOs in the country. (Dessalegn,2002)

On the other hand, since the early 1990s, some NGOs begun to rethink their role in development and have been considering making advocacy the integral part of their functions to scale up their influence even in the domain of 'development'. But this has some bearings on the nature of existing relations between NGOs and Government as it is evident in the recent proclamation which effectively bared international NGOs from involving in such practices (Charities and Societies Proclamation, No.621/2009). Even though this proclamation may have some positive contribution on the governance of CSOs in general, it has also significant negative implications for the engagement of this sector in general in terms of both size and scope (Dessalegn et al, 2008).

As expected in Campbell's frame work, NGOs activity in the areas of relief and development is more likely to be welcomed by governments, while their involvement in advocacy is more likely to be considered as a threat- even to survive and carry out their 'traditional' functions in some political cultures. In Ethiopia, in spite of a relative opining up of space for such opportunity since early 1990s, it was not effectively used by NGOs for various reasons including their own weakness (Kassahun,2002). Whatever the case, in spite of their significant contributions for local development, their development and engagement is still very limited when we consider the recent expansions by the sector worldwide.

\section{VI.RESULT AND DISCUSSION}

The original objective of this study was to deal with all INGOs that are functional on 'regular' base in the study area. However, WVE is found to be the only organization with such characteristics. While we may benefit from dealing with diverse actors, here, we are compelled to deal with the experience of WVE in the study areas. However, still this case by itself will be considered within the general experience of NGOs in Ethiopia. World Vision is international NGO which is established in 1950 and currently operates transnationally in more than 100 countries (World Vision Ethiopia, 2012).As "a global Christian relief, development and advocacy organization", the organization claims that it is "dedicated to working with children, families and communities to overcome poverty and injustice" without any discrimination (Ibid: 3). To execute such global mandate, it has established different structures at different levels extending from global down to ADPs at grass root level. Within this frame work, this section highlights the experience of WVE in general; and then attempts to focus on specific cases based on the objectives and the conceptual frame work set for the purpose of this study.

Like many other NGOs, WVE begun operation in Ethiopia as a response to the famine crisis in the country in 1971. Followik8ng this intervention, it formally opened office in 1975. However, its contribution for about a decade was limited in the areas of "relief, rehabilitation and small community development projects". Its massive contribution during the second famine crises in 1984/85 was also in line with the general approach by the organization during this period (World Vision Ethiopia, 2012:3).

\section{A- LOCAL DEVELOPMENT CONCEPTION AND PRIORITIES}

In explaining WV's development conception, ADP managers in the study area refer to the identity and vision of their organization. For example, one ADP manager begins with a remark that WV is a Christian organization which aspires to serve humanity in its fullness. To put it differently, his point is that to enable people worship God, we have to work with the poor to release their potential in much broader sense. Related to this, the organization's focus on 'ensuring sustained well-being of children seems more strategic in the organization's work of assisting local development on sustainable way by focusing on the future generation. Accordingly, all other activities by the organization in the area are largely geared towards achieving this strategic goal.

Historically, as indicated above, WV begun its engagement in Ethiopia to respond to the famine crises. However, along other 'second generation' NGOs, it begun to shift its approach and engagement towards “integrated development approach" which aims at 'empowerment' and 'transformation' by supporting more sustainable development (Annual Report, 2012). In this context, the organization's national strategic plan for the years (2013-2015) and the following set priorities for such engagement have been guiding the operations at ADP level. Generally, while the organization's position on what it calls "cross cutting issues" remains vague, other priorities are clearly articulated as:

1. Food Security: Improve household food security status, resilience to shocks and recovery from disasters

2. Health and Nutrition: Improve health and nutritional status of children and pregnant and lactating women

3. Education: Improve access to quality education

4. Water, Sanitation and Hygiene (WASH): Improve access to adequate WASH practices

5. Child Protection: Promote child protection, participation and spiritual development

6. Environment/Climate Change: Ensure climate resilient sustainable development 
7. Disaster Risk Reduction and Emergency Response: Improve community resilience to shocks and response to disasters (World Vision Ethiopia, 2012)

Overall, WV's engagement in the community is based on the above conception about its role in local development and the set priorities as a guide for its intervention. Accordingly, it is imperative to reflect on the organization's tangible contributions in the study area at least based on these priorities.

\section{B- PRACTICAL CONTRIBUTIONS}

To begin with the selection of the area, WV officials in the area claim that it is based on three criteria set by the organization and consultation with government bodies at different levels. These criteria include- existing development gap, development potential and accessibility. As such, decision on the distribution of ADPs begins at regional level and continue down to woredas by taking the issue of fairness as well. Accordingly, WV is operating in these two woredas of West Wollega zone since 2006/7.However, beyond their general willingness to discuss on basic issues, WV officials in the study area declined to offer me any formal report regarding their activities by claiming that it is against the policy of their organization. In this context, this section relays on the summary of data gained from West Wollega Zone Finance and Economic Development office and specific reactions by WV and government officials on these activities. (See Table 1, appendix)

From this data, what we may observe is that the organization has allocated a significant resource that might benefit a significant portion of the community. There is no question that this means a lot where there is scarcity of resource to finance development. However, it tells us little on how it is actually used and what are the actual impacts. In this context, for whatever reason, the issue of transparency is problematic and it is a paradox; when the organization which is supposed to teach transparency is not willing even to disclose its activities for the purpose of academic study.

At any rate, reflections by the organization's officials may shade some light on their activities. For example, they claim that they are working in partnership with local government bodies, FBOs, CBOs and the community at large to build their capacity. Regarding their areas of focus, WV official at Lalo Assabi claims "as development NGO we focus on transformational development in the areas of education, health, potable water supply, food security, and climate change by aligning with government policy." As specific case, another WV official at Najo also claims that they provided improved crop hybrids for 2662 households in 2013 to assist food security. However, as Mr. Brehanu asserts, "all these activities are based on supporting children at different levelsdirect support for children within their community, building family capacities, and community based services."

So, all these activities converge with the organization's set priority areas in its strategic plan for 20132015. Rather, what seems more important is, as discussed by Lewis and Kanji (2009)their 'innovative' approach to compliment government efforts like 'literacy boost'- the establishment of informal literacy centers and the adoption of different models like GINII- focusing on women and food security based on garden farms as the experiences at Najo attests.

\section{C- CONVERGENCE/DIVERGENCE OF APPROACHES}

The relevant officials from both sectors claim that they have generally good relations mainly because of the convergence/complementarity of their approach to local development. For example, despite his concern about the lack of transparency in reporting, one local government official who is responsible to supervise the activities of NGOs at Zone level claims that "all activities by WV in the area are based on development ....and our approaches more or less converge or at least compliments each other." This is also in line with evaluations by WV managers in the study area. Lalo Assabi ADP manager confirms that they have good relations because as a 'development NGO' they are closely working with all "government bodies and the community from planning to implementation." A little beat in a different way another WV official at Najo Mr. Admassu agrees with such overall assessment in the following way:

"Our approach is based on supporting government strategies and MDG because we inter in to agreement with government starting from project design...Even if there is a difference technically at field level, we are working with the community and local government bodies without any friction."

Generally, existence of such 'convergence' and smooth relationship at grass root level can be explained by two concepts we have discussed earlier. First, according to the frame work developed by Campbell (1996), the relationship between NGOs and States depend on two factors- activities performed by NGOs and regime types. (See Table 1) Because WV mainly portrays itself as 'development NGO' and it is not active in the areas of human rights and 'advocacy', it is more likely that it maintains good relation with all regime types except military dictatorship. Of course, the engagement of INGOs in the areas of human rights promotion and advocacy is legally prevented in Ethiopia since 2009. Second, according to Lewis and Kanji (2009) NGOs play three basic roles in the contemporary development practice- Service delivery, Catalysis and Partnership. Even though big NGOs including WV are now contemplating on the importance of how to be 'political' for development (Bell,2010), the 
focus on partnership and 'supporting government strategies'- as expressed by one WV staff may raise doubt about the nature of such positive relationship. As such, partnerships may take two forms- active and dependent. While partnership is constructive when it is active, based on lively negotiation and learning how to work together, it is still instructive to note the following remark about the experience of NGOs in Africa in general: Belligerence and assertiveness might be counter-productive. But if NGOs become subservient, and go for self-aggrandizement even at the expense of their declared principles and underlying ideals, they lose out on the both sides and capitulate. Hence there is a need for striking the right balance between the two extremes- of accommodation and confrontation (Kassahun, 2002: 125)

\section{D- IDENTITY AS TRANSNATIONAL ACTOR: OPPORTUNITY OR CHALLENGE?}

The organization's identity- whether it is how the organization defines itself or how it is perceived by others, determines its function and relations with others. WV defines itself as "a global Christian relief, development and advocacy organization dedicated to working with children, families and communities to overcome poverty and injustice." (World Vision Ethiopia, 2012) In line with this, ADP manager of WV at Lalo Assabi explains why all their development projects are geared towards the promotion of child wellbeing to enable them experience the love of God in its fullness. But this is not to say it discriminates people because of its identity and focus.

In addition, even though we may consider it as development NGO which is apolitical, most 'third generation' NGOs including WV are now explicitly focusing on the importance of advocacy at different levels (Bell, 2010). However, at national level, the fact that it is INGO have also affected its operation in some issue areas because some areas are allowed only for local NGOs by the 2009 proclamation. In this context, while the 2003-2004 strategic plan by WVE states that it also works on cross cutting issues like gender, advocacy and conflict, WV officials in the study area tend either to down play or scape questions related to it. Whatever the case, its identity as INGO may have prevented it to engage in some issue areas at national level.

Beyond this, while it is possible to emphasize on resource opportunities related to the organization's identity as international NGO, itis also related to misperceptions and expectations which are out of the organization's intention. For example, official from WV is concerned about the community perception/expectation and the development of dependency syndrome. To be specific, he complains that while their approach requires different forms of participation by the community- it can be idea, labor, resource, there is a tendency of expecting full support from the organization alone. However, according to one community member the real concern is the discrepancy between what is expected from such 'big' organization and most activities by the organization in the area. In his own words,

Most activities are of only small scale projects which don't benefit the whole community. Most activities [that are] carried out by the organization can even be done by local NGOs.... the organization has to widen its vision as its name indicates and plan big projects as it is an International NGO to play its role in solving big problems in the community. (Interview with Mr. Mulgeta at Najo)

Generally, these perceptions/expectations can be considered from the perspective of transnationalism as how contemporary interactions at global scale is shaping public attitude at local level. In addition, it also tells us that these transnational actors are actually functioning in different contexts and they have to negotiate with diverse actors at different levels. As such, they need to listen to the community on regular bases and consult with relevant actors even to be acknowledged as significant by the community they are actually serving.

\section{VII- CONCLUSION AND THE WAY FORWARD}

Fundamentally, this study attempts to explore the experience of World Vision at grass-root level in its development endeavor. However, to put it in broader context, it approached the issue deductively within the frame work of the emerging paradigm of transnationalism. In this context, by highlighting the experience of NGOs in Ethiopia, the study explored the experience of this specific organization in Lalo Assabi and Najo woredas.

Like other NGOs, World Vision begun its operation in Ethiopia to respond to the famine crisis. While its engagement was limited, gradually it has broadened its approach to development like other second generation NGOs. Based on this re-defined "integrated development approach" it has established area development programs (ADPs) in 1990. Lalo Assabi and Najo are among such ADPs for the organization's grass-root operation.

Generally, the organization's development practice seems to be guided by both altruism and strategic considerations. The claim that as a Christian organization they "aspire to serve humanity in its fullness" is clearly altruistic. Yet, the explanation of the same claim instrumentally- in the sense that it "enable people to worship God fully" has also strategic aspect. Moreover, every engagement in the community is strategically linked to assist development on sustainable base by supporting next generation within their community.

In the study area, the organization claims that it has significant practical contributions in the areas of education, health, potable water supply, food security, and environmental protection. However, in all this areas, rather than 
initiating or recommending alternative ways to solve development problems, it tends to focus more on 'capacity building' by working with the established institutions. However, as a more significant and commendable contribution, it has also adopted some innovative ways of solving specific problems like establishing informal literacy centers and the adoption of unique models to support vulnerable groups in terms of food security.

The relationship between ADPs and local government bodies seems to be generally smooth as it is expected according to Campbell's framework. First, officials from both side claim that 'development' is their common cause. Second, World vision officials in the area claim that their approach is based on partnership and they are working with all stake holders beginning with the planning process all the way to the implementation. Nevertheless, while there is still some concern about transparency and regular reporting by the side of local government, World Vision officials emphasize on the complementarity of their activities even when there is some difference technically at field level. In a net shell, the existing positive relationship is related to the resources at their disposal, focus on local development as permissible area, and their approach on how to work in 'partnership' in the context of existing legal frame work.

Moreover, the organizations identity as transnational actor has also significant bearings on its image, autonomy, and relations with other stake holders. First, this is the age when most 'development' NGOs including World Vision are moving to be 'political' and begun to recognize the importance of advocacy even for 'development' at global scale. However, at national level, some governments continue to be reluctant and suspicious about such organizations. While they may allow such organizations to support development in strict sense, they are more likely to be regarded negatively if they expand their engagement beyond the conventional 'service' provision. Second, they have to also consult with the local community on how to serve them; and occasionally deal with undesirable expectations and the development of dependency syndrome as one ADP official is complaining about. So, obviously different factors and attitudes about them can still affect their operation at grass-root level.

At any rate, this study has tried to explore one specific role of such transnational actors based on World Vision's experience. While this can be considered as a proper reaction to the demands of the contemporary age's complexity, it is still limited in terms of scope and depth. As such, further study may extend such effort by dealing with different local contexts and organizations within the same frame work or from different perspectives. In this regard, the relationship between INGOs and local civil society organizations deserves much attention to improve our knowledge of this sector. Beyond this, the role of other power full transnational actors like MNCs and their relations with NGOs and even governments still needs much investigation.

\section{REFERENCES}

[1] Ataman, M. (2003). The Impact of Non-State Actors on World Politics: A Challenge to Nation-States. Alternatives: Turkish Journal of International Relations, Vol.2, No.1, 42-66.

[2] Bell, P. (2010).The Role of Global NGOs in World Politics: The Case of Relief and Development Organizations. Centre for International Policy Studies: University of Ottawa.

[3] Campbell, W. (1996). The potential for donor mediation in NGO-State relations: An Ethiopian case study. IDS/IDR.

[4] Clark, J. (2006). Worlds Apart: Civil Society and the battle for ethical Globalization. First South Asian Edition. Earth Scan publications: London.

[5] De Waal, A. (1997). Famine crimes: Politics and the Disaster Relief Industry in Africa. London: James Carrey.

[6] Dessalegn R. (2002).Civil Society and Development in Ethiopia. In Bahiru Z. and Pausewang, S. (Eds).Ethiopia: The challenges of democracy from Below. Addis Ababa: Forum for social studies.

[7] Dessalegn R., Akalewold B., and Yoseph E. (2008). CSOs/NGOs in Ethiopia: Partners in Development and Good Governance. A Report Prepared for the Ad Hoc CSO/NGO Task Force. Addis Ababa.

[8] Edwards, M and David H. (1992). Making a difference: NGOs and development in changing world. Earth scan: London.

[9] Federal Negarit Gazeta (2011). Charities and Societies Proclamation. No. 621/2009.

[10] Fowler, A. (1991). The Role of NGOs in changing state societies relations: Perspectives

[11] from Eastern and Southern Africa in Development Policy Review, vol.9. pp.53-84.

[12] Gran, G. (1983). Development by people: Citizen construction of a just world. New York: Palgrave.

[13] Kaldor, M. (2003). Global Civil Society: An Answer to War. Polity press: Cambridge.

[14] Kassahun B. (2002). The Role of NGOs in protecting democratic values: The Ethiopian experience. In Bahiru Z. and Pausewang, S. (Eds). Ethiopia: The

[15] challenges of democracy from Below. Addis Ababa: Forum for social studies. pp.120-129.

[16] Keohane, R. and Nye, J. (1971). Transnational Relations and World Politics. Cambridge: Harvard University press. 
[17] Korten, D. (1987). Third generation NGO strategies: a key to people-centered development. World Development.

[18] Lewis, D. and Kanji, N. (2009). Non-governmental Organizations Development. London: Routledge.

[19] Ministry of Justice (2007). Database on Associations and Registered. Addis Ababa.

[20] Mostashari, A. (2005). An Introduction to Non- Governmental Organization (NGO) Management. Iranian Studies Group at MIT.

[21] Nye, J. (2007). Understanding International Conflicts: An Introduction to Theory and History. (6 ${ }^{\text {the }}$ edn). Pearson Education.

[22] Plan Ethiopia (2006). Meta-Evaluation of Projects and Programs on Community Managed Rural Water Supply and Sanitation Services in Ethiopia.

Rourke, J. (2005). International Politics on the World Stage. $10^{\text {th }}$ edn. Mc Grew Hill: New York.

[23] Vakil, A. (1997). Confronting the classification problem: toward a taxonomy of NGOs. World Development 25, 12: 2057-71.

[24] World Bank (2002).Empowerment and Poverty Reduction: A Sourcebook. Washington DC.

[25] World Vision Ethiopia (2012). Annual Report. http:// Accessed on May3,2015.

\section{Appendix}

Table 1. Data on WV's budget and beneficiaries in Lal Assabi and Najo ADPs. Source- Compiled from the information from West Wollega Finance and Economic Development Office.

\begin{tabular}{|l|l|l|l|l|l|l|l|}
\hline \multirow{2}{*}{ ADP } & \multirow{2}{*}{ Budget } & \multicolumn{6}{|l|}{ Beneficiaries } \\
\cline { 3 - 8 } & & \multicolumn{2}{|l|}{ Direct } & Indirect \\
\cline { 3 - 8 } & & M & F & T & M & F & T \\
\hline Lalo Assabi & $36,000,000$ & 23,380 & 17,770 & 41,150 & 20,350 & 21,765 & 42,115 \\
& $(2015-2016)$ & & & & & & \\
\hline Najo & $\begin{array}{l}49,783,500 \\
(2013-2017)\end{array}$ & 7,480 & 6,912 & 14,400 & 500 & 440 & 940 \\
& & & & & & \\
\hline
\end{tabular}

Table 2.List of interviewees

\begin{tabular}{|l|l|l|l|}
\hline Name & Position & Place & Date \\
\hline Admasu Bulti & WV official & Najo & $18 / 02 / 2016$ \\
\hline Assefa & $\begin{array}{l}\text { WestWollega zone } \\
\text { administration } \\
\text { Finance department. } \\
\text { official, }\end{array}$ & Gimbi & $07 / 02 / 2016$ \\
\hline Brehanu Gebre Senbet & WV ADP manager & Lalo Assabi, Inango & $04 / 02 / 2016$ \\
\hline Gutu Gobena & WV official & Lalo Assabi, Inango & $04 / 02 / 2016$ \\
\hline Mulugeta Efrem & Teacher & Najo & $18 / 02 / 2016$ \\
\hline Yeshiye Yisma & WV ADP manager & Najo & $09 / 04 / 2015$ \\
\hline
\end{tabular}

